\title{
ISSUES AND CHALLENGES IN LIBRARY SYSTEM MIGRATION: A CASE STUDY IN INDIA
}

\author{
Dr. Niraj Barua \\ Librarian, B. Borooah College, \\ Ulubari, Guwahati, Assam, India
}

\begin{abstract}
Library system migration is imperative for providing more efficient services and adopting new technology. System migration is not an easy task and its success depends on various factors. This paper discusses as a case system migration in the Rev. B. M. Pugh Library of Assam Agricultural University (RBMPL-AAU) and the findings from this study would be beneficial for management and staff to refine system migration task in future.
\end{abstract}

Key words: Integrated Library System, Library staff, System migration, Technology, University library

Cite this Article: Dr. Niraj Barua, Issues and Challenges in Library System Migration: A Case Study in India, India. International Journal of Library \& Information Science, 7(2), 2018, pp. 55-60.

http://iaeme.com/Home/issue/IJLIS?Volume=7\&Issue $=2$

\section{INTRODUCTION}

The library and information centre occupies a unique position as the hub of all the teaching and learning activities in an educational institution. Being an integral part of this process it supports academics through dissemination of knowledge from its vast information resources and pooling together the efforts of modern information professionals and information technology (IT). With the help of IT the housekeeping activities of the modern library and information center have been automated to a large extent to provide efficient information services to the users. To keep pace with the rapid changes in IT, libraries and information centers invariably has to adapt by periodically migrating its systems to newer technology.

A library system migration normally involves upgrading from one Integrated Library System (ILS) to another ILS which may or may not be from the same vendors. Sometimes migration might involve also hardware up gradation and sometimes it may include shifting from a proprietary based ILS to Open Source Software ILS (OSS ILS). Whatever may be the process system migration in libraries is a very costly, time consuming and risky job involving huge bibliographic data and, transaction records and administrative settings. 
The data in the library management systems includes the catalogue records holdings information and detail of who has borrowed material from the stock and these are generated as a result of various information processing activities in libraries. Library Automation software are integral part of any library system. The migration process in the library from an old system to a new one is very complicated process especially while doing so from fully proprietary based software which does allow access to its internal architecture. At the same time the integrity of the huge amount of bibliographic information needs to be ensured. The issue of system friendliness and motivating the library staff to work with the new system is also a major challenge.

\subsection{Problem Statement}

Migration is not an easy task. It has to be planned and executed in such a manner so as not to hamper the normal functioning of the library, without causing discomfort to the user and staff. Studies have reveled many problems as well as advantages of the migration process. Careful studies including feedback from managers, staff and users have to be done to identify drawback and benefits from the migration process. Recently the Rev B.M Pugh Library of Assam Agricultural University (RBMPL-AAU), Jorhat, Assam had undertaken a migration process from its existing library management system to a new one. The present study would investigate the drawbacks as well as the benefits accrued from the migration in RBMPL. Hence the following study was undertaken.

\subsection{Literature Review}

Clarke \& Morris (1998) in their migration study in Oxford University Library found that staff involvement is very crucial. If during the migration process all the staff are properly communicate it makes easier to understand what were the drawbacks of earlier system and how it could be rectified with the new system. Matoria \& Upadhyay (2005) opined that, proprietary softwares are not supportive in system migration in libraries. Since XML was compatible to RDBMS, it should be preferred as the exchange format rather than MARC etc. Wang (2009) in his research emphasized on the issue of vendors role in system migration and found that most of the libraries included in the study were satisfied. Vuksanoviü \& Sudareviü (2010) in their study on migration involving Integrated Library Management system found that it is comparatively easy to import and export simple bibliographic information from one system to another.

Singh (2017) found that most of the staff is satisfied to migrate to a Open Source Software ILS because of the low cost and range of functionalities. According to Zhu \& Spidal (2015) for a successful data migration the following lessons were learned: involve staff, elect a team leader, clean up data, communicate the timeline, make training work, design good testing data, go live with the new system, plan ahead, communicate with the vendor, and ensure a successful migration. Pund and Jain (2016) discusses that migration cannot be overlooked as a simple step. It is a complex process that holds various phases which make it prone to failure.

\subsection{Research Objectives}

The general objectives of the study are as follows:

- To find out the background information of staff in Rev B.M Pugh Library of Assam Agriculture University (RBMPL-AAU).

- To identify the problems encountered during migration process in RBMPL-AAU.

- To understand about the advantages and disadvantages accrued from the migration process in RBMPL-AAU. 


\subsection{Methodology}

The study adopted case study approach. This study has been conducted to identify the present situation of RBMPL-AAU in system migration. This study also tries to identify the challenges and opportunities of RBMPL-AAU during migration.

The principal tool used in the study for data collection was a questionnaire and reviews of documentary sources both primary and secondary. The questionnaire consisted of closed and open ended questions and the respondents were required to choose an answer whether Yes, No or don't know.For analysis of data, Microsoft Excel software had been used. After receiving all the completed questionnaires, data was entered in excel sheet and coding was done.

\section{DATA ANALYSIS AND INTERPRETATION:}

After carefully coding the data using MS excel, data analysis was carried out for the various set of responses from the staff. These are discussed below:

\subsection{Highest Qualifications of the Respondents}

The Highest qualification of the library staff working in RBMPL-AAU is tabulated below. It is clear from the TABLE 1 that $50.0 \%$ of the staffs are High school qualified, $37.5 \%$ staffs are Higher Secondary and $12.5 \%$ are Post graduate qualified.

Table 1 Highest Qualification of the Respondents

\begin{tabular}{|c|c|}
\hline Highest Qualifications & Frequency Count \\
\hline HSLC & 4 \\
\hline HS & 3 \\
\hline PG & 1 \\
\hline
\end{tabular}

\subsection{Professional Qualification of the Respondents}

TABLE 2 shows percentages of library staffs that had professional qualifications and percentages that did not in RBMPL-AAU. It is clear from the table that $50 \%$ Respondent are professionally qualified and $50 \%$ are none qualified.

Table 2 Professional Qualification respondents

\begin{tabular}{|c|c|}
\hline Qualification & Frequency Count \\
\hline YES & $4(50 \%)$ \\
\hline NO & $4(50 \%)$ \\
\hline
\end{tabular}

\subsection{Name of the Professional Qualification}

In the TABLE 3 shows that 37.5\% Respondents were Diploma Qualified 12.5\% Respondents were Bachelor degree in Library and Information Science (BLISc) qualified and 50\% are have no professional qualification.

Table 3 Name of the professional qualification

\begin{tabular}{|l|c|}
\hline \multicolumn{1}{|c|}{ Qualification } & Frequency Count \\
\hline Diploma & 3 \\
\hline BLISc & 1 \\
\hline No Professional qualification & 4 \\
\hline
\end{tabular}




\subsection{Difficult to Handle Computer System}

In the TABLE 4 shows that $62.5 \%$ of the respondents faced this problem always. $12.5 \%$ Respondents faced this problem never and 25\% Respondents faced this problem sometimes only.

Table 4 Difficult to handle computer system

\begin{tabular}{|c|c|}
\hline Difficult to handle computer system & Frequency Count \\
\hline Always & 5 \\
\hline Never & 1 \\
\hline Sometimes & 2 \\
\hline
\end{tabular}

\subsection{No Training on Current ILS System}

In the TABLE 5 shows that $37.5 \%$ respondents faced this problem always. $37.5 \%$ Respondents faced this problem never and $25 \%$ sometimes faced this problem.

Table 5 No training on current ILS system

\begin{tabular}{|c|c|}
\hline No training on current ILS system & Frequency Count \\
\hline Always & 3 \\
\hline Never & 3 \\
\hline Sometimes & 2 \\
\hline
\end{tabular}

\subsection{Data Entry is Complicated}

In the table 6 shows that the respondents found data entry process complicated. $62.5 \%$ respondents were faced this problem always and $37.5 \%$ faced this problem sometime only.

Table 6 Data Entry is complicated

\begin{tabular}{|l|c|}
\hline Data Entry is complicated & Frequency Count \\
\hline Always & 5 \\
\hline Never & 0 \\
\hline sometimes & 3 \\
\hline
\end{tabular}

\subsection{Inadequate Power Supply}

In the TABLE 7 shows that among the respondents $25.0 \%$ faced this problem always. $37.5 \%$ respondents faced this problem never and $37.5 \%$ faced this problem sometimes.

Table 7 Inadequate power supply

\begin{tabular}{|c|c|}
\hline Inadequate power supply & Frequency Count \\
\hline Always & 2 \\
\hline Never & 3 \\
\hline Sometimes & 3 \\
\hline
\end{tabular}

\subsection{Inadequate Staff}

In the TABLE 8 shows that among the respondents $25.0 \%$ respondents faced this problem always, $50.0 \%$ faced this problem never and $25.0 \%$ faced this problem sometimes only. 
Table 8 Inadequate staff

\begin{tabular}{|c|c|}
\hline Inadequate staff: & Frequency Count \\
\hline Always & 2 \\
\hline Never & 4 \\
\hline Sometimes & 2 \\
\hline
\end{tabular}

\subsection{Inappropriate Time Schedule}

In the table 9 shows that $25.0 \%$ staffs always faced this problem.12.5\% never faced this problem, whereas $62.5 \%$ faced this problem sometimes.

Table 9 Inappropriate time schedule

\begin{tabular}{|c|c|}
\hline Inappropriate time schedule & Frequency Count \\
\hline Always & 2 \\
\hline Never & 1 \\
\hline Sometimes & 5 \\
\hline
\end{tabular}

\subsection{Increase Work Efficiency}

From the TABLE 10 it is clear that $75 \%$ of the respondents felt that migration would increase their work efficiency. However $25 \%$ of the respondent felt otherwise.

Table 10 Increase work efficiency

\begin{tabular}{|c|c|}
\hline Will increase my work efficiency & Frequency Count \\
\hline Yes & 6 \\
\hline No & 2 \\
\hline
\end{tabular}

\subsection{Gain New Knowledge}

In the TABLE 11 shows that among the respondents $87.5 \%$ respondents found they gain new knowledge and $12.5 \%$ respondents felt otherwise.

Table 11 Gain new knowledge

\begin{tabular}{|c|c|}
\hline Will gain new knowledge & Frequency Count \\
\hline Yes & 7 \\
\hline No & 1 \\
\hline
\end{tabular}

\subsection{Improve Career Opportunity}

In the TABLE 12 shows that $37.5 \%$ respondents felt that migration will help in their career opportunity and $62.5 \%$ respondents felt otherwise.

Table 12 Improve career opportunity

\begin{tabular}{|c|c|}
\hline Will help in my career opportunity & Frequency Count \\
\hline Yes & 3 \\
\hline No & 5 \\
\hline
\end{tabular}




\section{FINDINGS}

From the data collection on the background information of the respondents, It shows that 4 respondent (50\%) were High school qualified, (37.5\%) respondents were higher secondary qualified and $(12.5 \%)$ respondents are graduate qualified. It is clear from the table 2 that $(50 \%)$ respondents are professionally qualified and $(50 \%)$ are none qualified. In the table 3 shows that (37.5\%) Respondents were Diploma Qualified (12.5\%) Respondents were BLISc qualified and (50\%) did not have any professional qualification. The present study shows that during migration process the problem "difficult to handle computer system" was responded by $62.5 \%$ as "Always". $12.5 \%$ of the respondents never faced this problem "never" and $25 \%$ of the respondents aced this problem "Sometimes". With regard to the problem "No training on current LMS system", $37.5 \%$ of the respondents faced it "Always", $37.5 \%$ of the respondents faced it "never" and $25 \%$ faced it "sometimes". On the problem "Data entry process complicated" the study revealed that $62.5 \%$ respondents faced this problem "Always" and $37.5 \%$ faced this problem "sometime" only.

"Inadequate power supply" was responded by $25.0 \%$ as "Always", $37.5 \%$ as "never" and $37.5 \%$ as "sometimes". On the problem "Inadequate staff", $25.0 \%$ faced it "Always", $50.0 \%$ faced this problem "never" and $25.0 \%$ faced it "Sometimes". About the problem "Inappropriate time schedule", $25.0 \%$ of the respondent faced this problem "Always", $12.5 \%$ "never" faced this problem, whereas $62.5 \%$ faced this problem "sometimes". With regard to the advantages accrued from the migration process it was found that $75 \%$ of the respondents felt that migration would "Increase the work efficiency". $87.5 \%$ of the respondents feel that they have "Gained knowledge" from the migration process. However $62.5 \%$ of the respondents felt that the migration process will not help to "Improve career opportunity".

\section{CONCLUSIONS}

This study has been on the Issues and challenges in library system migration in RBMPLAAU. With the advent of new technology and growth of information technology it becomes necessary to migrate the data from legacy system to more advanced one. Through understanding of purpose of migration, proper migration design and predicting the migration output can bring down the possible chance of failure drastically. Therefore, being aware of modern software and technology and current issues in data migration execution of steps became easier and can prove to be critical in successfully accomplishing a migration process.

\section{REFERENCES}

[1] Clarke, L., \& Morris, A., Library System Migration:A Case Study of Change Management at Oxford University. Libri , 48,1998,153-162.

[2] Matoria, R. K., \& Upadhyay, P. K. , Migration of data from one library management system to another:a case study in India. Program: electronic library and information systems , 29(2), 2005,160-166.

[3] Petrijevpanin, I., \& Sudareviü, B., 52nd International Symposium ELMAR-2010.

[4] Pund, M. \& Jain, P., System and Process for Data Transformation and Migration from Libsys to Koha, International Research Journal of Engineering and Technology, 2016, 690-702.

[5] Singh, V., Open source integrated library: Librarians share the lessons learnt, Journal of Librarianship and Information Science, 2017,1-10.

[6] Wang, Z., Integrated Library System (ILS) Challenges and Opportunities: A Survey of U.S. Academic Libraries with Migration Projects, The journal of Academic Librarianship, 35(3), 2009, 207-220. 